\title{
Spontaneous Novelty Seeking and Amphetamine-induced Conditioning and Sensitization in Adult Mice: Evidence of Dissociation as a Function of Age at Weaning
}

\author{
Walter Adriani, and Giovanni Laviola
}

Individual differences in coping with novelty and in the response to psychoactive drugs have been related to early life events, such as the age of weaning. Outbred CD-1 mice underwent a precocious (postnatal day (pnd) 15, Wean-15 group), regular (pnd 21, Wean-21 group), or delayed (pnd 27, Wean-27 group) weaning, and were tested as adults (pnd > 60). In Experiment 1, animals underwent a treatment history with d-amphetamine (AMPH 0, 1, or 5 $\mathrm{mg} / \mathrm{kg}$ once/day for three days) in a familiar environment. On testing day, mice were challenged with SAL or a standard $1 \mathrm{mg} / \mathrm{kg}$ AMPH dose (to evaluate acute drug effects and sensitization), and placed in the familiar environment. As expected, regular Wean-21 animals showed an AMPH-induced hyperactivity and a profile of conditioned locomotion, whereas the same dosage failed to induce any change in Wean-15 and Wean-27 groups. Levels of spontaneous novelty seeking were particularly elevated for Wean-27 mice, when compared with the other weaning groups. In Experiment 2, pairing of AMPH administration
$(0,1,2,3.3$, or $5 \mathrm{mg} / \mathrm{kg}$ once/day for three days) with a distinct environment produced a classical conditioned place preference. The magnitude of the preference profile was significantly more marked for Wean-15 mice, when compared with the other two weaning groups. Both experiments also provided evidence that the development of sensitization was particularly evident in Wean-27 mice. In summary, delayed weaning was associated in adult mice with both elevated levels of novelty seeking and increased sensitization to drug effects. Conversely, animals weaned precociously were much more responsive to AMPHinduced incentive conditioning. These results appear relevant to the issue of early experiences as possible risk factors for a number of psychiatric disorders in humans, including the abuse of drugs.

[Neuropsychopharmacology 27:225-236, 2002] (C) 2002 American College of Neuropsychopharmacology. Published by Elsevier Science Inc
From the Section of Behavioural Pathophysiology, Lab. Fisiopatologia O.S., Istituto Superiore di Sanitá, viale Regina Elena 299, I-00161 Roma, Italy.

Address correspondence to: G. Laviola, Section of Behavioural Pathophysiology, Lab. Fisiopatologia O.S., Istituto Superiore di Sanitá, viale Regina Elena 299, I-00161 Roma, Italy. Tel.: 39-06-49902105; Fax: 39-06-495-7821; E-mail: LAVIOLA@ISS.IT

Received April 5, 2001; revised August 28, 2001; accepted December 3, 2001.

Online publication: $1 / 31 / 02$ at www.acnp.org/citations/ Npp013102237.
KEY WORDS: Weaning; Amphetamine; Conditioning; Sensitization; Novelty seeking

Apart from the individual genetic background, individual differences in the seeking for novelty and in vulnerability to drug abuse may also be the consequence of critical experiences occurring early in life. There is indeed a growing literature investigating the effects of precocious manipulations upon brain and behavioral regulations in animal models (for a review, see Laviola and Terranova 1998). In this context, the gradual transition to nutritional and behavioral independence, which 
takes place at weaning, can well be seen as a centerpiece in development. This is a period of neural and behavioral organization, and hence a potential vulnerability of CNS structures can be hypothesized (Greenough et al. 1990). Moreover, whereas the date of weaning is fixed in most rodent studies around the end of the third postnatal week, weaning is a gradual phenomenon under natural conditions (Galef 1981). Individual differences in the process of separation from the mother might lead to hormonal and behavioral consequences that contribute to the natural variability of phenotypes (Cirulli et al. 1997).

Experimental manipulation of weaning time in cats and rats has been shown to affect a wide range of facets of the adult behavioral repertoire: specifically, it has been suggested that pups may adaptively respond to precocious weaning by speeding up subsequent development (Bateson et al. 1990). Accordingly, when compared with a regular weaning group, animals weaned precociously show a number of behavioral (Martin and Bateson 1985; Terranova and Laviola 1995; Loggi et al. 1996; Terranova et al. 2000) and neurochemical (see e.g. Sharman et al. 1982; Mann and Sharman 1983) changes, which can be regarded as signs of advanced ontogeny. Conversely, it has been shown that weaning itself acts as a developmental stimulus for the expression and onset of functional control of a specific opioid receptor (delta subpopulation), and that a late weaning may delay such development (Muhammad and Kitchen 1993; Kitchen et al. 1994; see also Terranova and Laviola 2001). Dopaminergic CNS systems have been reported to undergo maturation during the pre- and post-weaning period (Rao et al. 1991; Teicher et al. 1995; Moll et al. 2000). The individual organization of this neurobehavioral system might hence be affected by an early or a delayed separation from the lactating dam. Indeed, age at weaning is reported to affect the development of the dopaminergic system as well as the response to dopaminergic drugs (Cirulli et al. 1997; Laviola \& Dell'Omo 1997).

It has been recently suggested that the activation of brain mesolimbic pathways, which are involved in reward-related phenomena and motivation (Robbins and Everitt 1996; Wise 1996), share a common neurobiological substrate with the active search of novelty and other natural rewarding sensations (Benjamin et al. 1996; Bardo et al. 1996). Experimental evidence indicates that the experience of novelty activates the mesolimbic system, because entering a novel environment is associated in rats with an elevation of dopamine levels within the nucleus accumbens (Rebec et al. 1997). Furthermore, lesions of this area, induced by 6-OHDA, block the expression of novelty seeking behavior (Pierce et al. 1990). Thus, the satisfaction of a novelty-stimulated "curiosity" seems to have most of the characteristics of natural rewarding events (Renner 1990).
Surprisingly, only few data are available upon the effects of a manipulation of the weaning variable upon novelty seeking and drugs' reinforcing effects (see e.g. Laviola and Dell'Omo 1997). The first aim of the present study was to assess whether the manipulation of weaning time would account for individual differences in a specific behavior, such as novelty seeking, that has been correlated with vulnerability to drugs of abuse in both animals (Bardo et al. 1996; Dellu et al. 1993; Laviola et al. 1999) and humans (Wills et al. 1994; Zuckerman 1994). The second aim of the present work was to assess the effects of either precocious or delayed weaning upon the locomotor response to amphetamine (AMPH) as well as AMPH-related incentive conditioning. To address these aims, animals underwent either a precocious (on postnatal day (pnd) 15) or a delayed (on pnd 27) weaning, and were compared with a control group of mice weaned regularly (on pnd 21). When adults, animals were tested in two experimental settings. In Experiment 1, acute and carryover AMPH effects, as well as levels of spontaneous novelty seeking, were assessed. In Experiment 2, a separate group of animals was tested in order to assess weaning-related changes in the actual strenght of drug-induced place conditioning. In both experiments, profiles of locomotor sensitization following repeated psychostimulant administration were also investigated.

\section{MATERIALS AND METHODS}

\section{Subjects, Breeding, and Rearing Conditions}

Mice of the outbred CD-1 strain, without prior breeding experience, were purchased from a commercial breeder (Charles River Italia). On arrival, mice were housed in an air-conditioned room (temperature $21 \pm 1^{\circ} \mathrm{C}$, relative humidity $60 \pm 10 \%$ ), with a reversed 12-hr lightdark cycle (lights on at 9:00 P.M). Water and food (Enriched Standard Diet purchased from Mucedola, Settimo Milanese, Italy) were available ad libitum. After two weeks, breeding pairs were formed and housed in plexiglas cages $(33 \times 13 \times 14 \mathrm{~cm})$. After approximately two weeks, the male was removed, and the females were housed individually and inspected daily for delivery. Although only male subjects were used in the present experiment, litters were culled to six males and three females on pnd 1 (to avoid potential carry-over effects of rearing animals in a sexual segregation condition during the pre-weaning period, see Laviola and Dell'Omo 1997). Separate litters were randomly assigned to three different weaning groups, namely, precocious (Wean-15), regular (Wean-21), or delayed (Wean-27). On pnd 14, all litters were given some food pellets on the floor of the cage, to facilitate independent feeding at an early stage (Laviola and Terranova 1998). At weaning, the mother was removed, three littermates being housed 
in each cage $(33 \times 13 \times 14 \mathrm{~cm})$. Sibling mice within each litter were assigned to separate experimental groups. All animals were tested at adulthood (pnd $>60$ ).

\section{Apparatus}

The experimental apparatus consisted of an opaque Plexiglas rectangular box with smooth walls, subdivided into two compartments $(20 \times 14 \times 27 \mathrm{~cm})$. The connecting door between the two compartments could be closed by means of a temporary partition. Two cues, one visual and one tactile, were associated with each compartment. One compartment was white and had a wide-mesh floor, whereas the other one was black and had a narrow mesh floor. Each compartment was provided with four infrared photobeams, placed on the wall $(2 \mathrm{~cm}$ above the floor). Each beam interruption caused by a mouse was recorded by an IBM computer equipped with custom software. The floor of the apparatus was cleaned after each animal was tested. The following measures were obtained automatically: (1) time spent in each compartment; and (2) activity rate in each compartment (number of beam interruptions per second). The whole session was automatically subdivided into 5-min intervals. The whole experimental schedule took a total of six days, each subject from all three age groups being tested between 10.00 A.M. and 6.00 P.M. Testing of different experimental groups was counterbalanced across time. The test was carried out under dim illumination. The same two-compartment apparatus was used in both experiments.

\section{Experiment 1: Novelty Preference Paradigm}

One compartment of the apparatus (white side) was the familiar one, whereas the other compartment (black side) was the novel one (see Laviola and Adriani 1998). The preference for the novel compartment has been shown to be independent from the environmental cues provided (Bardo et al. 1993).

Day 0: Familiarization. Animals were marked on the tail, and immediately placed for $20 \mathrm{~min}$ in the familiar compartment of the apparatus.

Days 1, 2, 3: Pre-treatment period. Animals were weighed and randomly assigned to a regimen of AMPH injections $(0,1$, or $5 \mathrm{mg} / \mathrm{kg}$ i.p.) within each litter. Immediately after the injection, animals were placed in the familiar compartment of the apparatus for a 20-min session.

Day 4 (wash-out). A wash-out interval of $48 \mathrm{~h}$ was left between the last day of pre-treatment (Day 3 ) and the test (Day 5), in order to avoid the influence of residual circulating levels of AMPH during the testing session.

Day 5: Novelty preference test. Mice were randomly assigned for a challenge with either saline (SAL) or a stan- dard AMPH dose $(1 \mathrm{mg} / \mathrm{kg})$. Animals were weighed, injected i.p. and immediately placed in the familiar compartment, for a 20-min session. The partition separating the two compartments of the apparatus was then removed, and mice were thus allowed to freely explore the whole apparatus (both the familiar and the novel sides) for $15 \mathrm{~min}$.

\section{Experiment 2: Place Conditioning Paradigm}

The white compartment of the apparatus was the drugpaired one, whereas the other compartment was the SAL-paired one. This "biased" procedure is often reported in the literature on place conditioning (see Laviola et al. 1994).

Day 0: Familiarization. Animals were marked on the tail, and allowed to freely explore the whole apparatus for a 20-min session, in a drug-free state.

Days 1, 2, 3: Pairing period. On each of these days, all animals were injected with SAL and placed in the black compartment of the apparatus for a 20-min session. Mice were then returned to their own cages for a 5-min rest period. At the end of this period, animals were injected with AMPH $(0,1,2,3.3$, or $5 \mathrm{mg} / \mathrm{kg}$ i.p.) and placed in the white compartment of the apparatus for a 20 -min session. This procedure was not counterbalanced, i.e. AMPH administration always followed the SAL injection, to avoid potential residual AMPH effects that would interfere with the SAL-pairing to the other compartment. Within each litter, a control mouse received a SAL injection before being placed in either compartment. Only five mice per litter were used in this experiment.

Day 4. A 48-hour interval was left between the last pairing and the test.

Day 5: Place conditioning test. Mice were allowed to freely explore the whole apparatus for a 20-min session, in a drug-free state.

\section{Drugs}

D-amphetamine (AMPH) sulfate was dissolved in saline (SAL, $\mathrm{NaCl} 0.9 \%$ ) and injected i.p. in a volume of 1 $\mathrm{ml} / 100 \mathrm{~g}$ body weight. AMPH doses were chosen in the range of those used in previous studies (see Laviola and Adriani 1998; Adriani et al. 1998). Doses are expressed in salt weight.

\section{Design and Data Analysis}

Data were analyzed separately by a split-plot ANOVA (Chiarotti, Alleva, and Bignami 1987; Winer 1971), where the litter was the block variable: weaning was a between-litters factor, whereas all the other variables were within-litter factors. 
Experiment 1. The general design of the experiment was a 3 weaning (pnd 15,21 , or 27$) \times 5$ litter $\times 3$ treatment history $(0,1$, or $5 \mathrm{mg} / \mathrm{kg}$ AMPH dosage $) \times 2$ challenge (testing day dose: 0 or $1 \mathrm{mg} / \mathrm{kg}$ of $\mathrm{AMPH}) \times 2$ phase (Before or After the partition opening), as well as repeated measures on the same individual. For reasons of symmetry, in the 20-min session before the partition opening, only the first $15 \mathrm{~min}$ were considered, and these were compared with the 15-min session which followed the partition opening. A side variable (Familiar or Novel) was specifically used to analyze activity data following partition opening. Separate analyses were performed when allowed by a significant main effect of a given factor. Multiple comparisons within a significant interaction were performed using the Tukey HSD Test.

Experiment 2. In order to study the development of sensitization to AMPH, we analyzed data on activity rate expressed within the drug-paired compartment during the pairing period. The dependent variable was the percentage increase of locomotor activity, shown by drug-treated mice, calculated respect to the level expressed by the control SAL-injected sibling within each litter. Similarly, in order to study the incentive properties of $\mathrm{AMPH}$, we analyzed data expressed during the place-preference test. The dependent variable was the percentage increase of time spent in the drug-paired side, shown by drug-pretreated mice, calculated with respect to the level expressed by the control SAL-injected sibling within each litter. The general design of the experiment was a 3 weaning (pnd 15, 21, or 27) $\times 6$ litter $\times 4$ dose $(1,2,3.3$, or $5 \mathrm{mg} / \mathrm{kg} \mathrm{AMPH})$, as well as repeated measures on the same individual.

\section{RESULTS}

\section{Experiment 1: Novelty Preference Paradigm}

Activity rate. As a whole, the animals' activity rate was higher after the opening of the partition than before (main effect of phase, $\mathrm{F}_{1,9}=426.24, p<.01$ ), thus confirming that the discovery of a novel environment produces a marked arousal in mice. AMPH-related acute effects, conditioning and sensitization were then examined in the first phase of the test (before the partition opening).

A main effect of the challenge was found in the general ANOVA $\left(\mathrm{F}_{1,9}=21.11, p<.01\right)$, thus confirming the expected AMPH-induced hyperactivity. In order to investigate potential carry-over influences of differential weaning upon the acute response to $\mathrm{AMPH}$, a preliminary statistical analysis was limited to activity data from animals which underwent a treatment history with SAL, i.e. mice receiving the drug for the first time (see white bars in Figure 1). Interestingly, the ANOVA revealed a significant interaction of challenge, weaning and phase $\left(\mathrm{F}_{2,9}=6.54, p<.05\right)$. Multiple comparisons revealed that acute AMPH effects on locomotion were only observable in adult animals that were weaned regularly $(p<.01)$, whereas the same dose failed to induce any change in the other two weaning groups.

To evaluate conditioning, a separate analysis was also performed on data from the group injected with SAL on testing day. A significant treatment history by phase interaction appeared $\left(\mathrm{F}_{2,18}=19.57, p<.01\right)$. Specifically, a clear-cut and dose-dependent conditioned increment in activity rates was evident, in animals with an AMPH 5 treatment history (see Figure 1, left side of each panel). Interestingly, time of weaning also affected the expression of the conditioning profile (weaning $\mathrm{X}$ treatment history $\mathrm{X}$ phase, $\mathrm{F}_{4,18}=4.57, p<$ .01). In particular, AMPH 1 treatment history animals from the regular Wean-21 group showed a significant conditioned elevation of activity levels, when compared with the corresponding SAL treatment history controls $(p<.01)$. Conversely, no reliable evidence of conditioning to the AMPH 1 dose was found for the other weaning groups.

To evaluate the development of sensitization, drug effects were evaluated within AMPH treatment history groups (see Figure 1). The general ANOVA yielded a significant weaning $X$ challenge $X$ treatment history interaction $\left(\mathrm{F}_{4,18}=2.56, p<.05\right)$. Specifically, within the Wean-15 and Wean-21 groups, no significant effect of the AMPH challenge was found (namely, no significant differences between AMPH-challenged and SAL-challenged mice were evident) within AMPH treatment history groups. In these two weaning groups, a significant difference between AMPH 5 and SAL treatment histories was actually found in AMPH-challenged mice, but the latter was already evident in SAL-challenged mice (see above): Such effect is an evidence of conditioning, not sensitization. Conversely, within the Wean-27 group, the difference between AMPH 5 and SAL treatment history mice was much greater within the AMPH-challenged group than it was within the SAL-challenged group. In this weaning group, the AMPH challenge actually induced a significant hyperactivity (when compared with the corresponding SAL-challenged group) in AMPH 5 treatment history mice. This is noteworthy, since no significant effect of the AMPH challenge was found within the SAL treatment history group for Wean-27 mice (as reported above). In conclusion, repeated administration of the high drug dose potentiated the subsequent response to the AMPH challenge. Such an evidence of sensitization was only limited to lateweaning mice, and was conversely absent in the other two weaning groups.

During the novelty seeking test (i.e. after the partition opening, see Figure 2, upper panels), activity rates followed a classical habituation profile (repeated mea- 

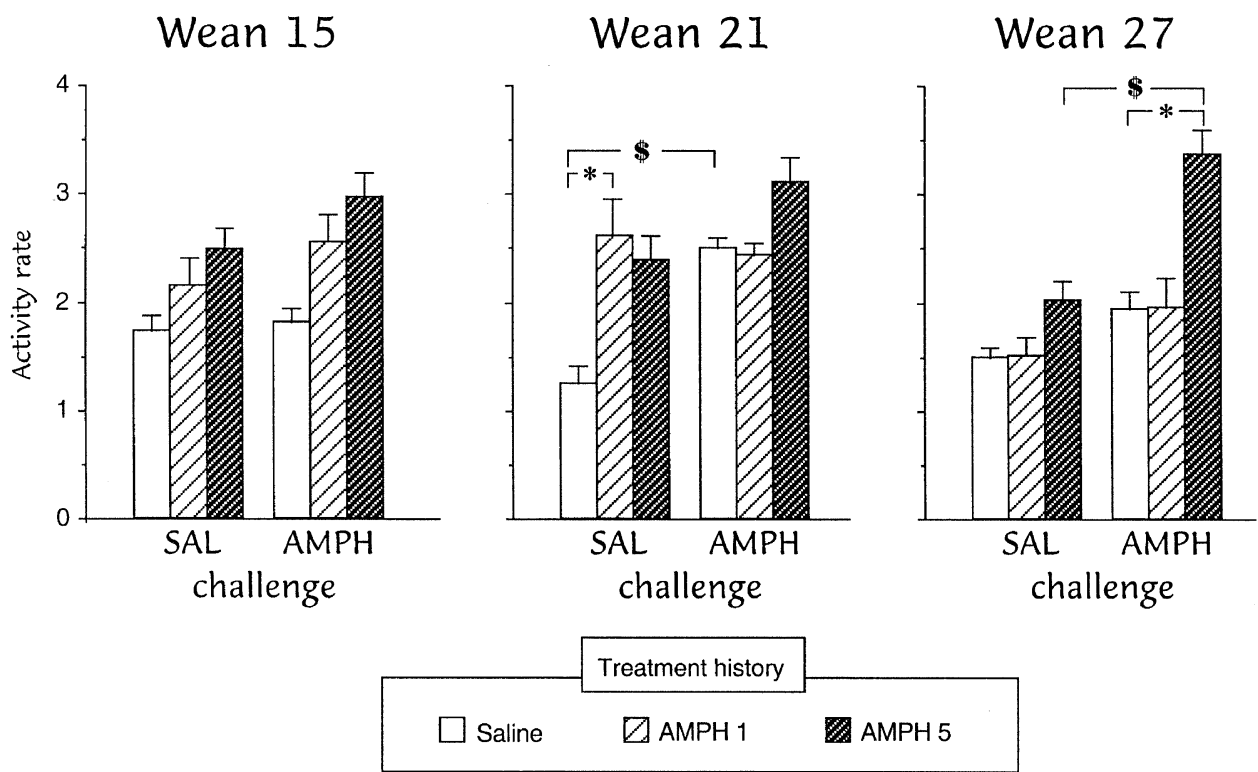

Figure 1. Experiment 1. Mean ( \pm S.E.M.) activity rate (number of photobeam interruptions / sec), shown before partition opening. During the pre-treatment period (days 1, 2 and 3), subjects were injected daily with AMPH (Treatment history: 0, 1, or $5 \mathrm{mg} / \mathrm{kg}$ ) and immediately placed for $20 \mathrm{~min}$ in the familiar compartment. On testing day, animals were challenged with either SAL or a standard AMPH dose $(1 \mathrm{mg} / \mathrm{kg})$ and placed in the familiar and pretreatment-paired compartment for 20 min. ${ }^{*} p<.05$ in multiple comparisons performed between subjects with different treatment histories; ${ }^{\$} p<.05$ in multiple comparisons performed between SAL- and AMPH-challenge groups.

sures, $\left.\mathrm{F}_{2,18}=82.01, p<.01\right)$, and were also under the influence of the side variable (familiar vs. novel environment). Indeed, a main effect of side $\left(\mathrm{F}_{1,9}=113.01, p<\right.$ $.01)$ revealed that mice were in general less active in the novel environment than in the familiar one. Furthermore, in order to investigate potential carry-over effects of differential weaning and of each animal's treatment history, a separate analysis was carried out on data from the SAL-injected group. A four-way significant interaction of weaning, treatment history, side and repeated measures was found $\left(\mathrm{F}_{8,36}=3.05, p<.01\right)$. As a whole, weak and not reliable effects of treatment history appeared (data not shown). Interestingly, time of weaning strongly affected the baseline profile, expressed by mice with a SAL treatment history. As expected (see Laviola and Adriani 1998), when compared with the familiar one, a significant reduction of activity in the novel compartment was found. Interestingly, Wean-15 mice discriminated clearly between the two sides of the apparatus at the early beginning of the test session $(p<.05)$, whereas the other two weaning groups expressed such a phenomenon around the middle of the session ( $p s<.05)$. As a whole, acute effects of an AMPH challenge were in the direction of a further reduction of activity in the novel environment (challenge $\mathrm{X}$ side interaction in the general ANOVA, $\mathrm{F}_{1,9}=$ $6.24, p<.05)$. However, no significant effects of either weaning or treatment history emerged on this profile (data not shown).
Novelty seeking. Following the opening of the partition, all subjects exhibited as expected a marked preference for the novel environment. The ANOVA carried out on data from the SAL-injected group revealed a significant interaction of weaning, treatment history and repeated measures $\left(\mathrm{F}_{8,36}=3.19, p<.01\right)$. As a whole, weak and not reliable effects of treatment history were found (data not shown). Interestingly, time of weaning strongly affected the baseline novelty seeking profile (shown by SAL treatment history groups, see Figure 2, lower panels). Specifically,when compared with the regular Wean-21 group, mice from the Wean-15 group spent significantly more time in the novel compartment at the beginning of the session $(p<.05)$, with levels of novelty seeking showing a fast decline thereafter. Interestingly, late-weaning (Wean-27) mice spent as a whole significantly more time in the novel environment $(p<$ .05 ), than the other two weaning groups (see also inset in Figure 2).

As expected on the basis of previous work (Laviola and Adriani 1998), the ANOVA carried out on data from the AMPH-challenged group revealed carry-over effects of treatment history with the same drug (treatment history $\mathrm{X}$ repeated measures, $\mathrm{F}_{4,36}=2.86, p<.05$ ). Specifically, AMPH 1 treatment history mice showed consistently lower levels of novelty seeking than the corresponding SAL treatment history controls, whereas an opposite profile was evident for those subjects with an AMPH 5 treatment history. Since no significant 
Wean 15
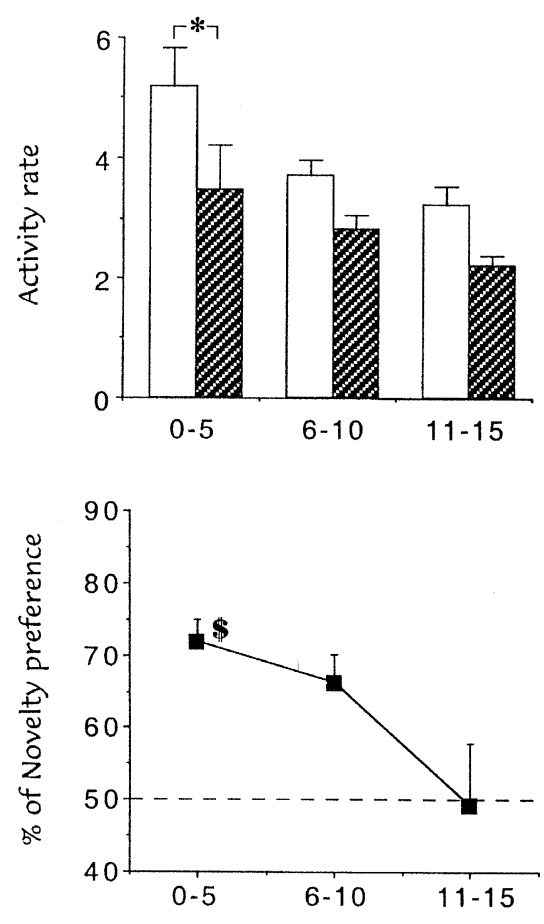

Wean 21

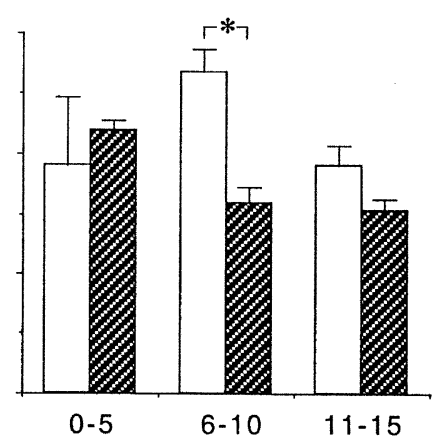

Wean 27
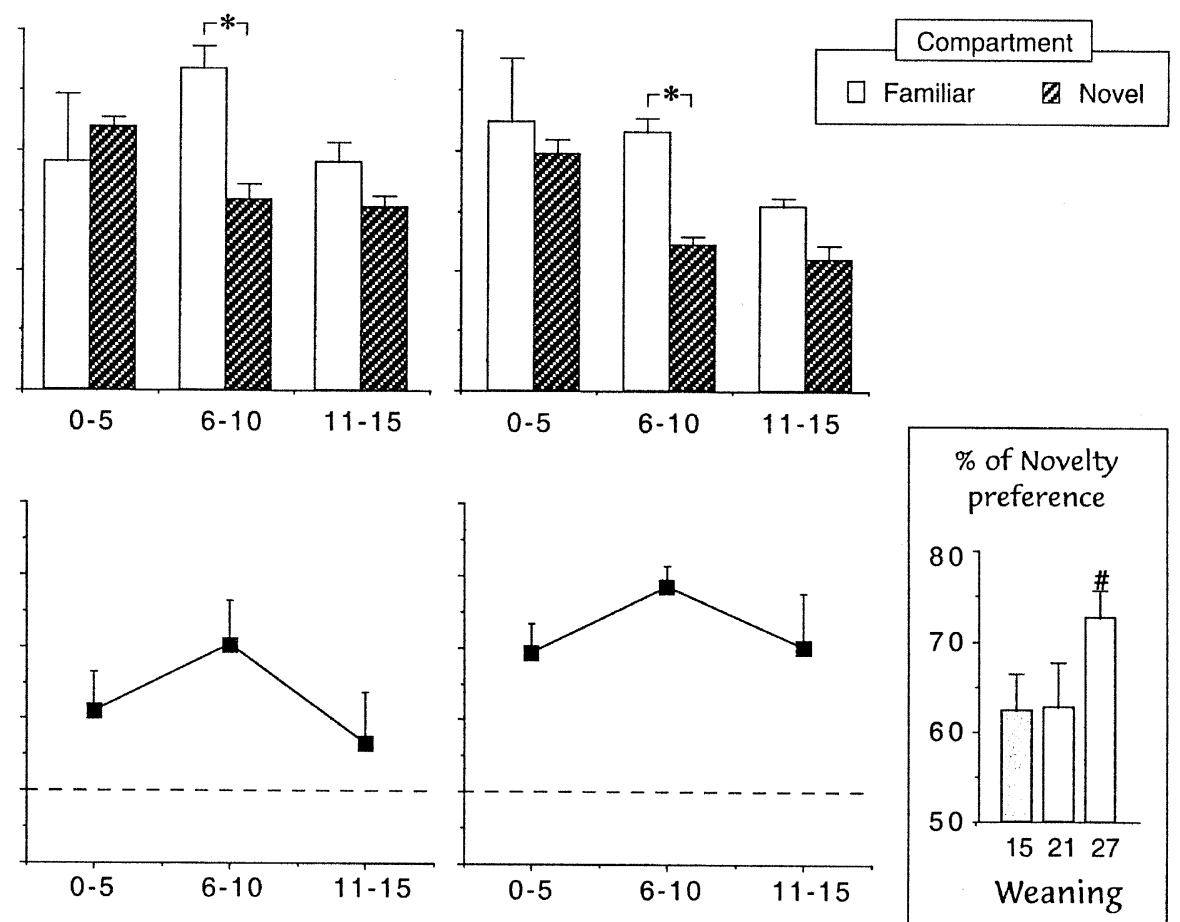

Minutes

Figure 2. Experiment 1. Upper panels: Mean ( \pm S.E.M.) activity rate (number of photobeam interruptions / sec), shown after partition opening as a function of the side variable (familiar vs. novel compartment). Lower panels: Mean ( \pm S.E.M.) percentage of time spent in the novel compartment (the three timepoints have been also collapsed as shown in the inset). Only drug-naive subjects are presented. After 20 min spent in the familiar and pretreatment-paired compartment, a partition was removed, and mice were allowed free-choice access to a novel compartment of the apparatus for a single 15-min session. ${ }^{*} p<.05$ in multiple comparisons performed between the novel and the familiar compartment; ${ }^{\$}$ and ${ }^{\#} p<.05$ in comparison to novelty seeking levels shown by regularly weaned subjects (Wean-21 group):

carry-over effects of time of weaning were found, data are not shown.

Body weight. To monitor the influence of repeated AMPH administration, animals were weighed during the whole experiment. The ANOVA yielded an interaction between day and treatment history $\left(\mathrm{F}_{6,126}=4.26, p<\right.$ .001). Specifically, animals which underwent a repeated AMPH 5 administration were associated with a significant decrease (approximately 2.3\%) in body weight on days 2 and 3 of the pretreatment period, when compared with the SAL treatment history group. No significant carry-over effects of time of weaning were found (data not shown).

\section{Experiment 2: Place Conditioning Paradigm}

Assessment of sensitization. The development of sensitization to drug effects was analyzed by carrying out an ANOVA on activity data from the pairing period (see Methods). Specifically, levels of locomotion expressed on the third day were compared with those ex- pressed on the first day of the schedule (see Figure 3). A main effect of dose $\left(\mathrm{F}_{3,45}=27.4, p<.001\right)$ confirmed the expected dose-dependent increment in locomotion induced by the drug. The ANOVA yielded a main effect of day $\left(\mathrm{F}_{1,15}=8.75, p<.01\right)$, that is, drug effects were significantly more marked on the third day than on the first one. Interestingly, significant carry-over effects of weaning appeared in the AMPH-induced sensitization profile, as confirmed by the finding of a weaning by day interaction $\left(\mathrm{F}_{2,15}=4.12, p<.05\right)$. Specifically, within the Wean-27 group, AMPH-treated subjects showed much higher drug-induced hyperactivity on day 3 , when compared with day 1 . Conversely, such a profile was not found in the other two weaning groups. Such a finding indicates that sensitization to the activating effects of repeated AMPH administration developed more readily within the late-weaning group.

Place conditioning. On testing day, in the absence of significant carry-over effects of the weaning variable $\left(\mathrm{F}_{2,15}=3.42, \mathrm{~ns}\right)$, a slight baseline preference for the black compartment appeared (see Table 1). In order to 

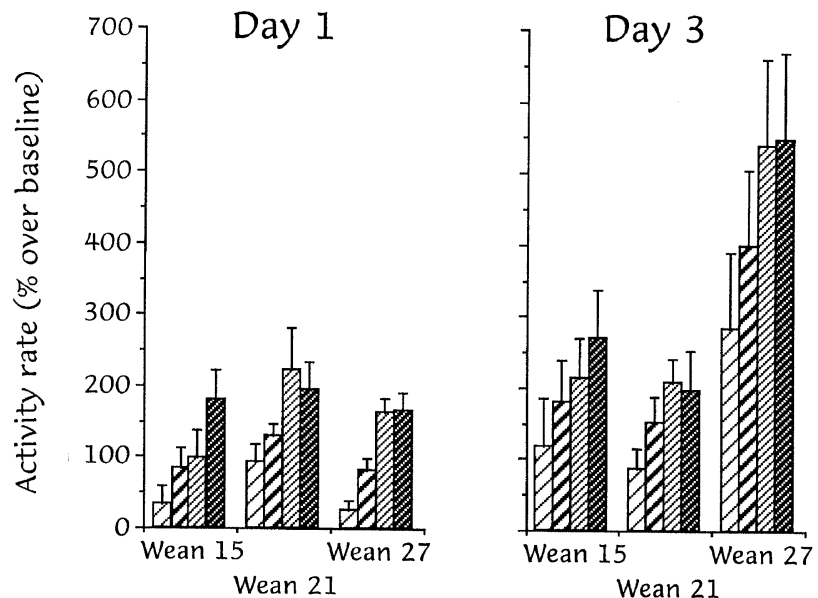

Wean 21

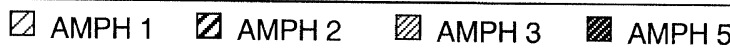

Figure 3. Experiment 2. Mean ( \pm S.E.M.) percentage increase of activity rate, shown by drug-treated mice, calculated respect to the control SAL-injected sibling within each litter. During the three-day pairing period, all subjects were injected with AMPH (dose: $0,1,2,3.3$, or $5 \mathrm{mg} / \mathrm{kg}$ ) immediately before being placed for $20 \mathrm{~min}$ in the white compartment.

assess the incentive properties of AMPH, an ANOVA was carried out on the percent increment in the preference for the drug-paired side, shown by drug-pretreated mice on testing day (see Figure 4). As expected, the analysis yielded a main effect of dose $\left(\mathrm{F}_{3,45}=4.52\right.$, $p<.01$ ), all the four AMPH doses producing a significant preference for the drug-paired compartment, with a peak at the AMPH 3.3 dose. Interestingly, an inverted U-shaped dose-response curve was found, the effect of the AMPH 5 dose reaching similar levels to that of the AMPH 1 dose.

The ANOVA also yielded a main effect of weaning $\left(\mathrm{F}_{2,15}=4.93, p<.05\right)$. Specifically, the preference profile for the drug-paired compartment was significantly more marked in Wean-15 mice, when compared with the other two groups. Weaning and dose variables however did not interact $\left(\mathrm{F}_{6,45}=0.29\right.$, ns), thus suggesting an upward shift in the dose-response curve (see Discussion).

Table 1. Mean \pm SEM percentage time spent in either side of the apparatus by control mice, as a function of weaning time

\begin{tabular}{lccc}
\hline & Wean-15 & Wean-21 & Wean-27 \\
\hline White compartment & $38.8 \pm 1.8$ & $44.1 \pm 1.8$ & $40.4 \pm 2.8$ \\
Black compartment & $61.2 \pm 1.8$ & $55.9 \pm 1.8$ & $59.6 \pm 2.8$ \\
\hline
\end{tabular}

During the pairing period of Experiment 2, control mice received a SAL injection before being placed in either compartment. On testing day, mice were allowed to freely explore the whole apparatus during a single 20-min session in a drug-free state.

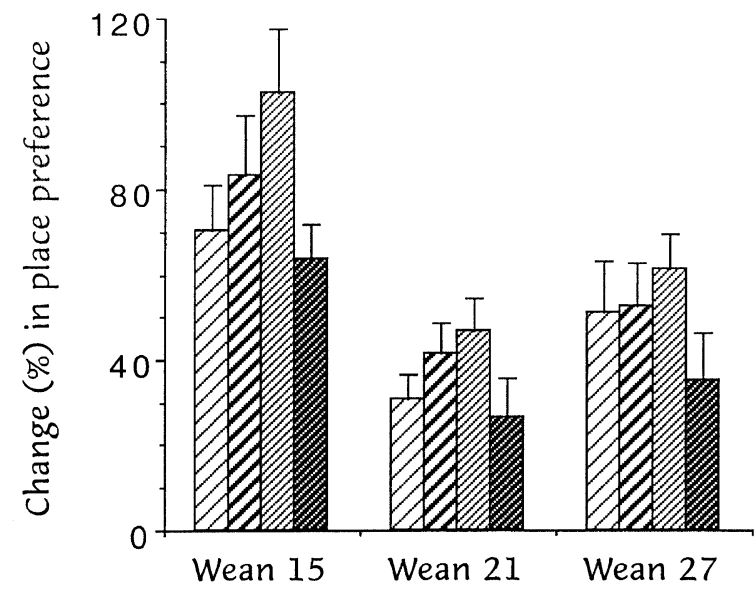

$\square$ AMPH $1 \square$ AMPH2 $\square$ AMPH 3 $\square$ AMPH 5

Figure 4. Experiment 2. Mean ( \pm S.E.M.) percentage increase of time spent in the drug-paired side, shown by drug-pretreated mice, calculated respect to the control SALinjected sibling within each litter. During the three-day pairing period, all subjects received an AMPH injection (dose: 0, $1,2,3.3$, or $5 \mathrm{mg} / \mathrm{kg}$ ) immediately before being placed for 20 min in the white compartment. On testing day, mice were allowed to freely explore the whole apparatus for $20 \mathrm{~min}$, without being injected.

\section{DISCUSSION}

As a whole, present data can be summarized as follows: 1. In Experiment 1, the unconditioned activating effects as well as the profile of drug-conditioned hyperactivity produced by a low AMPH dose were associated only with adult mice that were weaned regularly (Wean-21). Overall, the novelty seeking behavior was much more marked in mice that underwent a delayed weaning (Wean-27).

2. In Experiment 2, AMPH produced a clear-cut conditioned place preference for the drug-paired compartment. Interestingly, the magnitude of the drug-induced place conditioning was significantly more marked in precociously weaned mice (Wean-15), when compared with the other two weaning groups.

3. Both experiments provided evidence that, as a consequence of repeated AMPH administration, the development of a sensitization profile to the activating drug effects was particularly prominent in Wean-27 mice.

\section{Acute and Carry-over Effects of AMPH on Locomotion}

Experiment 1 allowed the assessment of acute AMPH effects, as well as carry-over effects of repeated treatment with the same drug. Acute administration of a low standard AMPH dose $(1 \mathrm{mg} / \mathrm{kg})$ produced a classi- 
cal hyperactivity profile in regularly weaned mice only, while no significant drug effects were found for the Wean-15 and Wean-27 groups. Consistently, following repeated administration of a low AMPH dose (1 mg/ $\mathrm{kg}$ ), a clear-cut and dose-dependent conditioning profile was observed (within the SAL-injected group on testing day) only in those animals that underwent a regular weaning, whereas no significant conditioning effects were found within the Wean-15 and Wean-27 groups upon this dose. Hence, as a long-term consequence of either precocious or delayed weaning, a reduced sensitivity to the $1 \mathrm{mg} / \mathrm{kg}$ dose (i.e. a shift to the right in the dose-response curve) can be suggested for the unconditioned locomotor effects as well as for the locomotor conditioning effects of AMPH. The present results indicate that manipulation of weaning time (i.e. either precocious or delayed weaning) was associated with important alterations in those CNS regulatory pathways, targetted by AMPH, which are responsible for unconditioned and conditioned hyperactivity.

Carry-over effects of weaning time on the development of sensitization to AMPH locomotor effects were assessed in both experiments. In Experiment 1: Within the Wean-27 group, as a consequence of the repeated pretreatment with the high AMPH dose, the AMPH challenge was able to produce a hyperactivity profile. This is noteworthy, since no reliable drug effects characterized mice receiving $\mathrm{AMPH}$ for the first time. In other words, although the AMPH challenge failed to induce any change in SAL treatment history mice, it did actually produce a significant increment of locomotion in the AMPH 5 treatment history group (i.e. it was now effective). The development of a sensitization phenomenon was thus revealed by the AMPH challengein late-weaning mice. Interestingly, such a profile was not found for the other two weaning groups.

A similar picture was also suggested by data from Experiment 2. Specifically, in the late-weaning group, subjects receiving repeated AMPH administration showed much higher drug-induced hyperactivity on the third day, when compared with the first day of the schedule. Such a profile was not found in either Wean-15 or Wean21 animals. Possibly, additional days of AMPH administration were needed by these animals to reach similar levels of sensitization. Therefore, at least with the doserange used, sensitization to the locomotor effects of a repeated AMPH administration readily developed only within the late-weaning group. As a whole, data from both Experiment 1 and Experiment 2 indicated that manipulation of age at weaning markedly affects the threshold for the development of sensitization to AMPH effects following repeated drug administration.

\section{Novelty Seeking and Novelty-induced Arousal}

As expected on the basis of previous reports (Misslin and Ropartz 1981; Bardo et al. 1996; Laviola and Adri- ani 1998), data from Experiment 1 indicated that, following the opening of a partition, all subjects showed a novelty-induced arousal as well as a clear-cut preference for the novel environment. Important carry-over effects of the manipulation of weaning time were found, in that the profile exhibited by Wean-15 mice consisted of a quick attraction for the novel environment, which was followed by a monotonic habituation trend. The latter may perhaps be ascribed to either a fast loss of interest for the novel environment, or to an increased distractibility (see e.g. Robbins et al. 1989). It might be interesting to note that such a behavioral profile toward novel stimuli characterized adult subjects which underwent a precocious separation from their mother. On the other hand, an opposite behavioral profile was exhibited by subjects allowed to stay longer with the dam. In fact, Wean-27 mice spent overall more time in the novel environment than the regular-weaning control group. Hence, a delay in weaning age resulted in adult individuals exhibiting a longer exploration of the novel environment.

It has been reported that levels of locomotion expressed during the exploration of the novel compartment are lower than those exhibited in the familiar one; that is, a slight behavioral inhibition is usually associated with a novel environment (Misslin and Ropartz 1981; Bardo et al. 1996; Laviola and Adriani 1998). Indeed, during exploration of a novel environment, mice are reported to express both approach (sniffing and smelling) and avoidance (stretched attend, stretched advance) reactions. This behavioral profile has been considered as an expression of risk assessment, i.e. a byside effect of concomitant assessment of potential danger in a completely unknown environment (Blois-Heulin and Belzung 1995; Blanchard et al. 1990; see discussion in Laviola and Adriani 1998). In the present study, a certain degree of behavioral inhibition was expressed in the novel environment always in association with peak levels in novelty seeking. Hence, a nice correlation was observed between novelty seeking and novelty-induced behavioral inhibition. Both these behavioral profiles were observed at an early timepoint during the session, as a long-term consequence of precocious weaning.

From an eco-ethological perspective, these results do indicate that manipulation of weaning time is able to exert an important long-term influence on the shaping of the individual response to novel stimuli. These findings appear to be highly relevant for the issue of individual variability in "coping styles" as a function of early life events (see also Laviola et al. 1999; Cirulli and Laviola 2000).

\section{AMPH-induced Place Conditioning}

As a whole, all the four AMPH doses tested in the present experiment produced a significant place prefer- 
ence for the drug-paired compartment. The dose-response curve consisted of an inverted U-shaped profile, with place preference increasing regularly to reach a peak at the $3.3 \mathrm{mg} / \mathrm{kg}$ dose, and decreasing thereafter. As a consequence, the levels associated with the AMPH 5 dose resulted actually similar to those of the AMPH 1 dose. Such a biphasic profile is not surprising. Indeed, following repeated administration of high AMPH dosages, adult rodents usually exhibit sensitization of stereotyped behavioral activity (Staton and Solomon 1984; Stewart and Badiani 1993). It can be hypothesized that the excessive arousal, repeatedly induced by high AMPH dosages during the pretreatment phase, might have produced, together with observable stereotypies, unobservable aversive effects ("poor welfare," see Laviola et al. 1994, 1995; Laviola and Adriani 1998), which were associated with the drug-paired compartment. Hence, a certain degree of conditioned aversion might have added to the background of incentive conditioning, causing a devaluation in the conditioned preference for the drug-paired side during the test (Baker et al. 1998; for a review, see Laviola et al. 1999).

Manipulation of weaning time strongly affected the profile of AMPH-induced place conditioning in adult subjects. In particular, drug-conditioned effects were significantly more marked in Wean-15 mice, when compared with the other two weaning groups. Consistently, previous reports associated early weaning with an increased sensitivity to cocaine's rewarding properties (Laviola and Dell'Omo 1997) and a higher responsivity to the modulatory effect of a delta-opioid agonist (Terranova and Laviola 2001), along with a numberof other neurobehavioral effects (Terranova and Laviola 1995; Loggi et al. 1996; Terranova et al. 2000). It seems important to note that manipulation of weaning time did not produce any leftward or rightward shift in the dose-response curve. Indeed, the latter reached a maximum at the $3.3 \mathrm{mg} / \mathrm{kg}$ dose and decreased at the $5 \mathrm{mg} /$ $\mathrm{kg}$ dose in all three weaning groups. The consequence of a precocious weaning was rather to enhance the magnitude of the place preference produced by each given dose. In other words, precocious weaning produced an upward vertical shift, rather an horizontal shift, in the dose-response curve (see Schenck and Partridge 1997; Piazza et al. 2000). A horizontal shift would indicate that a given dose in Wean-15 animals was equivalent to either a higher or lower one in control regular-weaning animals. This would perhaps suggest a change in pharmacokinetics and pharmacodynamics, leading to either reduced or increased drug levels at the active brain sites. Conversely, an upward vertical shiftpossibly suggests that increased synaptic and/or postsynaptic effects are produced by similar drug levels at the active brain sites. Such findings may suggest that the incentive efficacy of AMPH is somewhat increased in mice as a carry-over effect of precocious weaning.

\section{Behavioral Consequences of Precocious and Delayed Weaning}

Adult mice belonging to the late weaning group were associated with both elevated levels of spontaneous novelty seeking and a prominent sensitization to the activating effects of repeated drug administration. Since D1 receptors are known to mediate both behavioral sensitization and novelty seeking (Pierce et al. 1990; Bardo et al. 1993), present data may suggest an increased function of the D1 receptor subtype in lateweaning mice. Interestingly, a quite similar behavioral profile has been recently observed in mice during periadolescence (see Adriani et al. 1998), who also overexpress D1 receptors (Gelbard et al. 1989; Teicher et al. 1995). As for the elevated levels of novelty seeking behavior, it should be considered that the experience of novelty in a free-choice paradigm has been associated with dopamine release in reward-related brain areas (Rebec et al. 1997). It is possible to hypothesize that these animals may adopt a specific behavioral strategy (consisting of elevated novelty seeking levels) in the attempt to reach the threshold and stimulate the brain reward system, which is possibly set up at a low basal level (Stamford 1989). Similarly, the stress-response system has been reported to be basically down-regulated in rodents both during periadolescence (Choi et al. 1997; Adriani and Laviola 2000) and in adult subjects as a long-term consequence of delayed weaning (Cook 1999). From these evidences, a common neurobehavioral profile might characterize rodents both during periadolescence and in adulthood as a consequence of delayed weaning. It might hence be suggested that allowing animals to keep staying longer with their dam results in adult individuals that somewhat retain adolescent features.

A quite opposite profile was found in the case of subjects weaned precociously. Present results strongly indicate an increased sensitivity to AMPH-related positive reinforcing properties in these animals, as measured in a conditioned place preference paradigm. Similarly, an increased sensitivity to cocaine's rewarding effects has been reported in subjects weaned precociously (Laviola and Dell'Omo 1997), suggesting an increased sensitivity to psychostimulant-induced incentive conditioning. Since D2 receptor activation is known to be needed for the acquisition of place conditioning (Beninger et al. 1989), present data may suggest an increased function of the D2 receptor subtype in subjects weaned precociously. Moreover, Wean-15 mice from the present study were shown to be readily attracted by the novel environment, to which however they quickly habituated. This picture suggests a reduced threshold for novelty-induced reward. Precocious weaning might produce an elevation in the basal dopaminergic tone (see e.g. Sharman et al. 1982; Mann and Sharman 1983). 
As a whole, delayed weaning was associated in adult mice with enhanced AMPH-induced sensitization, whereas animals weaned precociously were more responsive to AMPH-conditioned incentive effects. This finding suggests a dissociation, in the long-term effects of manipulating the weaning time, between two important behavioral processes usually associated with a repeated AMPH administration (namely, place conditioning and the development of behavioral sensitization to drug effects). Actually, the neural pathway from ventral tegmental area to nucleus accumbens has been indicated as a neurobiological substrate for behavioral sensitization (Kalivas and Stewart 1991; Robinson and Berridge 1993), whereas the amygdala has been classically associated with a major role in drug-induced place conditioning (Everitt et al. 1991; McDonald and White 1993). A divergent degree of functional maturation of these two CNS areas cannot be excluded in the different weaning groups from the present study (see e.g. Cooke et al. 2000). Indeed, dopaminergic receptor systems have been reported to undergo maturation during the pre- and post-weaning period (Rao et al. 1991; Teicher et al. 1995; Moll et al. 2000), and the maturation of dopamine release appears to be site-dependent (Gazzara et al. 1986). Interestingly, previous ontogenetic studies with place conditioning reported an elevated sensitivity to both cocaine and AMPH between postnatal days 15 and 22 in mice (Laviola et al. 1994), whereas the ability to induce an adult-like profile of behavioral sensitization does not mature until pnd 21 (Ujike et al. 1995; Fujiwara et al. 1987). The individual organization and functional interplay between these two separate neurobehavioral systems might thus be affected differently by an early and more dramatic (or vice versa a delayed and perhaps less stressful) separation from the lactating dam.

\section{CONCLUSION}

The present study can be viewed in the light of the studies carried out by Bateson and colleagues (1990), which suggested an accelerated behavioral development as an adaptive response to precocious weaning, and conversely a delayed maturation as a (mal)adaptive response to late weaning. Present results confirm and extend previous observations suggesting that manipulation of weaning time, within a natural range of variation, is a powerful determinant of adult individual phenotype, affecting important aspects of the animal's neurobehavioral repertoire, namely (1) the behavioral reaction to both forced (see Loggi et al. 1996) and freechoice novelty (present data); and (2) the activating and affective properties of highly potent and addictive drugs, such as cocaine (Laviola and Dell'Omo 1997) and AMPH (present data).
In conclusion, natural changes in the time of weaning is one source of behavioral variability between individuals. This has potential implications for the issue of early life events as important risk factors for the development of a number of behavioral disorders, including drug abuse.

\section{ACKNOWLEDGMENTS}

This research was supported as part of the intramural grant to G.L., Research Project on "Psychobiological risk or protection factors for behavioral disorders and vulnerability to recreational substances abuse during development," Nervous and Mental Disorders Research Area, Istituto Superiore di Sanità, Italy, and by the "Fondo Nazionale per la Lotta alla Droga," Ministero per la Solidarietà Sociale, Italy. W.A. was supported by a "Giuseppe LEVI" bursary from the Accademia Nazionale dei Lincei, Italy. We wish to thank A. Valanzano for expert technical assistance, and Dr. M. Puopolo for help in statistical analysis. All tests have been performed following the guidelines of the European Community on the welfare of experimental animals, as listed in the Italian D.L. 116/92.

\section{REFERENCES}

Adriani W, Chiarotti F, Laviola G (1998): Elevated novelty seeking and typical d-amphetamine sensitization in periadolescent compared to adult mice. Behav Neurosci 112:1152-1166

Adriani W, Laviola G (2000): A unique hormonal and behavioral hyporesponsivity to both forced novelty and damphetamine in periadolescent mice. Neuropharmacology 39:334-346

Baker DA, Specio SE, Tran-Nguyen LTL, Neisewander JL (1998): Amphetamine infused into the ventrolateral striatum produces oral stereotypies and conditioned place preference. Pharmacol Biochem Behav 61:107-111

Bardo MT, Bowling SL, Robinet PM, Rowlett JK, Lacy M, Mattingy BA (1993): Role of dopamine D1 and D2 receptors in novelty-mantained place preference. Exp Clin Psychopharmacol 1:101-109

Bardo MT, Donohew RL, Harrington NG (1996): Psychobiology of novelty seeking and drug seeking behavior. Behav Brain Res 77:23-43

Bateson P, Mendl M, Feaver J (1990): Play in the domestic cat is enhanced by rationing the mother during lactation. Anim Behav 40:514-525

Beninger RJ, Hoffman DC, Mazurski EJ (1989): Receptor subtype-specific dopaminergic agents and conditioned behavior. Neurosci Biobehav Rev 13:113-122

Benjamin J, Li L, Patterson C, Greenberg BD, Murphy DL, Hamer DH (1996): Population and familial association between the D4 dopamine receptor gene and measures of novelty seeking. Nat Genet 12:81-84

Blanchard RJ, Blanchard DC, Weiss SM, Meyer S (1990): The effects of ethanol and diazepam on reactions to predatory odors. Pharmacol Biochem Behav 35:775-780

Blois-Heulin C, Belzung C (1995): Effects of previous famil- 
iarization on novelty reactions in mice. Behav Processes 34:197-212

Chiarotti F, Alleva E, Bignami G (1987): Problems of test choice and data analysis in behavioral teratology: The case of prenatal benzodiazepines. Neurobehav Toxicol Teratol 9:179-186

Choi SJ, Weisberg SN, Kellogg CK (1997): Control of endogenous norepinephrine release in the hypothalamus of male rats changes over adolescent development. Brain Res Dev Brain Res 98:134-141

Cirulli F, Adriani W, Laviola G (1997): Sexual segregation in infant mice: Behavioural and neuroendocrine responses to d-amphetamine administration. Psychopharmacology (Berl) 134:140-152

Cirulli F, Laviola G (2000): Paradoxical effects of d-amphetamine in infant and adolescent mice: Role of gender and environmental risk factors. Neurosci Biobehav Rev 24:73-84

Cook CJ (1999): Patterns of weaning and adult response to stress. Physiol Behav 67:803-808

Cooke BM, Chowanadisai W, Breedlove SM (2000): Postweaning social isolation of male rats reduces the volume of the medial amygdala and leads to deficits in adult sexual behavior. Behav Brain Res 117:107-113

Dellu F, Mayo W, Piazza PV, Le Moal M, Simon H (1993): Individual differences in behavioral responses to novelty in rats: Possible relationship with the sensationseeking trait in man. Personality and Individual Differences 15:411-418

Everitt BJ, Morris KA, O’Brien A, Robbins TW (1991): The basolateral amygdala-ventral striatal system and conditioned place preference: Further evidence of limbic-striatal interactions underlying reward-related processes. Neuroscience 42:1-18

Fujiwara Y, Kazahaya Y, Nakashima M, Sato M, Otsuki S (1987): Behavioral sensitization to metamphetamine in the rat: An ontogenetic study. Psychopharmacology (Berl) 91:316-319

Galef BG (1981): The ecology of weaning: Parasitism and the achievement of independence by altricial mammals. In Gubernick DJ, Klopfer PH (eds), Parental Care in Mammals. New York, Plenum Press, pp 211-241

Gazzara RA, Fisher RS, Howard SG (1986): The ontogeny of amphetamine-induced dopamine release in the caudate-putamen of the rat. Brain Res Dev Brain Res 28:213-220

Gelbard HA, Teicher MH, Faedda G, Baldessarini RJ (1989): Postnatal development of dopamine D1 and D2 receptor sites in rat striatum. Brain Res Dev Brain Res 49:123-130

Greenough WT, Whiters GS, Wallace CS (1990): Morphological changes in the nervous system arising from behavioral experience: What is the evidence that they are involved in learning and memory? In Squire LR, Lindelaub E (eds), The Biology of Memory, Symposia Medica Hoechst 23. New York: Schattauder. pp 159-185

Kalivas PW, Stewart J (1991): Dopamine transmission in the initiation and expression of drug- and stress-induced sensitization of motor activity. Brain Res Brain Res Rev $16: 223-244$

Kitchen I, Crook TJ, Muhammad BY, Hill RG (1994): Evidence that weaning stimulates the developmental expression of a delta-opioid receptor subtype in the rat. Brain Res Dev Brain Res 78:147-150

Laviola G, Dell'Omo G, Chiarotti F, Bignami G (1994): DAmphetamine conditioned place preference in developing mice: Relation with changes in activity and stereotypies. Behavioral Neuroscience 108: 514-524

Laviola G, Wood RD, Kuhn C, Francis R, Spear LP (1995): Cocaine sensitization in periadolescent and adult rats. J Pharmacol Exp Ther 275:345-357

Laviola G, Dell'Omo G (1997): Precocious weaning and changes in social variables during pre-puberty affect cocaine reinforcing properties in adult mice. Psychobiology 25: 163-170

Laviola G, Adriani W (1998): Evaluation of unconditioned novelty seeking and d-amphetamine conditioned motivation in mice. Pharmacol Biochem Behav 59:1011-1020

Laviola G, Terranova ML (1998): The developmental psychobiology of behavioral plasticity in mice: The role of social experiences in the family unit. Neurosci Biobehav Rev 23:197-213

Laviola G, Adriani W, Terranova ML, Gerra G (1999): Psychobiological risk factors for vulnerability to psychostimulants in human adolescents and animal models. Neurosci Biobehav Rev 23:993-1010

Loggi GP, Dell'Omo G, Laviola G (1996): Individual differences in response to psychological stress and chlordiazepoxide in adult mice: Relations with changes in early social milieu. Psychobiology 24: 147-153

Mann SP, Sharman DF (1983): Changes associated with early weaning in the activity of tyrosine hydroxylase in the caudate nucleus of the piglet. Comp Biochem Physiol C Toxicol Pharmacol 74:267-270

Martin P, Bateson P (1985): The influence of experimentally manipulating a component of weaning on the development of play in domestic cats. Anim Behav 33:511-518

McDonald RJ, White NM (1993): A triple dissociation of memory systems: Hippocampus, amygdala, and dorsal striatum. Behav Neurosci 107:3-22

Misslin R, Ropartz P (1981): Effects of metamphetamine on novelty-seeking behavior by mice. Psychopharmacology (Berl) 75:39-43

Moll GH, Mehnert C, Wicker M, Bock N, Rothenberger A, Ruther E, Huether G (2000): Age-associated changes in the densities of presynaptic monoamine transporters in different regions of the rat brain from early juvenile life to late adulthood. Brain Res Dev Brain Res 119:251-257

Muhammad BY, Kitchen I (1993): Effect of delayed weaning on opioid receptor control of swim stress-induced antinociception in the developing rat. Br J Pharmacol 109:651-654

Piazza PV, Deroche-Gamonent V, Rouge-Pont F, Le Moal M (2000): Vertical shifts in self-administration doseresponse functions predict a drug-vulnerable phenotype predisposed to addiction. J Neurosci 20:4226-4232

Pierce RC, Crawford CA, Nonneman AJ, Mattingly BA, Bardo MT (1990): Effect of forebrain dopamine depletion on novelty-induced place preference behavior in rat. Pharmacol Biochem Behav 36:321-352

Rao PAS, Molinoff PB, Joyce JN (1991): Ontogeny of dopamine D1 and D2 receptor subtypes in rat basal ganglia: A quantitative autoradiographic study. Brain Res Dev Brain Res 60:161-177 
Rebec GV, Grabner CP, Johnson M, Pierce RC, Bardo MT (1997): Transient increases in catecholaminergic activity in medial prefrontal cortex and nucleus accumbens shell during novelty. Neuroscience 76:707-714

Renner MJ (1990): Neglected aspects of exploratory and investigatory behavior. Psychobiology 18:16-22

Robinson TE, Berridge KC (1993): The neural basis of drug craving: an incentive-sensitization theory of addiction. Brain Res Brain Res Rev 18:247-291

Robbins TW, Everitt BJ (1996): Neurobehavioural mechanisms of reward and motivation. Curr Opin Neurobiol 6:228-236

Robbins TW, Jones GH, Sahakian BJ (1989): Central stimulants, transmitters and attentional disorder: A perspective from animal studies. In Savogden T, Archered T (eds), Attention Deficit Disorders: Clinical and Basic Research. Hillsdale, Lawrence Erlbaum Associates, pp 199-222

Schenck S, Partridge B (1997): Sensitization and tolerance in psychostimulant self-administration. Pharmacol Biochem Behav 57:543-550

Sharman DF, Mann SP, Fry JP, Banns H, Stephens DB (1982): Cerebral dopamine metabolism and stereotyped behaviour in early-weaned piglets. Neuroscience 7:1937-1944

Stamford (1989): Development and ageing of the rat nigrostriatal dopamine system studied with fast cyclic voltammetry. J Neurochem 52:1582-1589

Staton DM, Solomon PR (1984): Microinjections of d-amphetamine into the nucleus accumbens and caudate-putamen differentially affects stereotypy and locomotion in the rat. Physiol Psychol 12: 159-162.

Stewart J, Badiani A (1993): Tolerance and sensitization to the behavioral effects of drugs. Behav Pharmacol 4: 289-312

Teicher M, Handersen SL, Hostetter JC (1995): Evidence for dopamine receptor pruning between adolescence and adulthood in striatum but not nucleus accumbens. Brain Res Dev Brain Res 89:167-172

Terranova ML, Laviola G (1995): Individual differences in mouse behavioral development: Effects of precocious weaning and ongoing sexual segregation. Anim Behav 50:1261-1271

Terranova ML, Loggi G, Chiarotti F, Laviola G (2000): Attractivity and social preferences in mice (Mus musculus domesticus): The role of prepubertal sexual segregation and of precocious weaning. J Comp Psychol 114:325-334

Terranova ML, Laviola G (2001): Delta-opioid modulation of social interactions in juvenile mice weaned at different ages. Physiol Behav 73:393-400

Ujike H, Tsuchida K, Akiyama K, Fujiwara Y, Kuroda S (1995): Ontogeny of behavioral sensitization to cocaine. Pharmacol Biochem Behav 50:613-617

Wills TA, Vaccaro D, McNamara G (1994): Novelty seeking, risk taking and related constructs as predictors of adolescent substance use: An application of Cloninger's theory. J Subst Abuse 6:1-20

Winer BJ (1971): Statistical Principles in Experimental Design, 2nd ed. New York, McGraw-Hill.

Wise RA (1996): Neurobiology of addiction. Curr Opin Neurobiol 6:243-251

Zuckerman M (1994): Behavioral Expressions and Biosocial Bases of Sensation Seeking. Cambridge, Cambridge University Press 